\title{
DIDÁTICA DA LEITURA E DA ESCRITA: OU PARA CONSTRUIR CONVERSAS SOBRE ESTRELAS
}

\author{
READING AND WRITING TEACHING: \\ OR TO PRODUCE TALES ABOUT STARS
}

\section{ENSEÑANZA DE LECTURA Y ESCRITURA: O PARA PRODUCIR CUENTOS SOBRE LAS ESTRELLAS}

\author{
Jilvania Lima dos Santos Bazzo ${ }^{1}$ \\ Ezra Alberto Chambal Nhampoca ${ }^{2}$
}

\begin{abstract}
RESUMO
Neste trabalho, ao apresentarmos a concepção de alfabetização, defendida por Magda Soares (2016; 2017), e as discussões atuais em torno do aprendizado da escrita (Fumo e Girão, 2018; Rangel e Machado, 2012), pretendemos contribuir para o fortalecimento das pesquisas na área de educação, literatura e ensino voltadas, primordialmente, para a apropriação pelas crianças dos textos literários no processo inicial de aprendizagem de leitura e escrita. Partimos de uma discussão acerca da função social da literatura (TODOROV, 2010; BAZZO e CHAGAS, 2014) para o desenvolvimento integral das crianças, buscando evidenciar os aspectos teóricos e metodológicos subjacentes à ação docente - planejada, sistemática e intencional - com vistas à formação leitora e escritora na infância à luz da Didática.
\end{abstract}

PALAVRAS-CHAVE: Alfabetização. Literatura. Práticas de mediação literária. Didática.

\section{ABSTRACT}

In this paper, we present the conception of literacy, defended by Magda Soares (2016; 2017), and current discussions around writing learning (Fumo and Girão, 2018; Rangel and Machado, 2012), we also intend to contribute to the strengthening of research in the area of education, literature and education primarily aimed at children's acquisition of literary texts already in the beginning of the initial process of learning to read and write. We start from a discussion about the social function of literature (TODOROV, 2010; BAZZO and CHAGAS, 2014) for the integral development of children, seeking to highlight the theoretical and methodological aspects underlying the planned, with a view to the reading and writing formation in childhood across Didactics.

Submetido em: 20/09/2019 - Aceito em: 20/10/2019 - Publicado em: 28/12/2019.

${ }^{1}$ Professora Adjunta do Programa de Pós-Graduação em Educação, Departamento de Metodologia de Ensino área e Didática, do Centro de Ciências da Educação da Universidade Federal de Santa Catarina. Líder do Grupo de Estudos e Pesquisas em Didática e suas multidimensões.

${ }^{2}$ Universidade Eduardo Mondlane, Faculdade de Letras e Ciências Sociais, Departamento de Línguas, Secção de Línguas Bantu (Maputo, Moçambique). 
KEYWORDS: Literacy. Literature. Literary mediation practices. Didactics.

\section{RESUMEN}

En este trabajo, al presentar la concepción de alfabetización, defendida por Magda Soares (2016, 2017) y discusiones actuales sobre el aprendizaje de la escritura ((Fumo y Girão, 2018; Rangel y Machado, 2012), pretendemos contribuir al fortalecimiento de las investigaciones en el área de educación, literatura y enseñanza orientadas, primordialmente, a la apropiación por los niños de los textos literarios ya al comienzo del proceso inicial de aprendizaje de lectura y escritura. En el marco de una discusión sobre la función social de la literatura (TODOROV, 2010, BAZZO y CHAGAS, 2014) para el desarrollo integral de los niños, buscando evidenciar los aspectos teóricos y metodológicos subyacentes a la acción docente - planificada, sistemática e intencional - con vistas a la formación lectora y escritora en la infância.

PALABRAS CLAVE: Alfabetización. La literatura. Prácticas de mediación literaria. Didáctica.

\section{ALFABETIZAÇÃO, LITERATURA E INFÂNCIA: UMA TRÍADE IMPLICADA}

A arte interpreta o mundo e dá forma ao informe, de modo que, ao sermos educados pela arte, descobrimos facetas ignoradas dos objetos e dos seres que nos cercam. (TODOROV, 2010, p. 65)

Afinal, o aprendizado de como funciona o sistema alfabético-ortográfico da língua portuguesa é um processo natural? Basta inserir as crianças em contextos de letramento para que ela saiba fazer uso social da escrita? Essas questões, segundo Magda Soares (2016), estão presentes nos dias atuais tanto aqui no Brasil quanto em outras partes do mundo. Em países de língua inglesa, por exemplo, a divergência se manifesta por meio de duas perspectivas teóricas whole language e phonics. A primeira advoga em favor de um ensino natural, não explícito, assistemático e com foco na interação e nos aspectos socioculturais inerentes às práticas sociais de convivência humana. Já a segunda rejeita tal vertente e concebe a alfabetização como uma etapa de ensino explícito e sistemático de correspondência entre fonema-grafema (para a escrita) e grafemafonema (para a leitura), portanto, os aspectos linguísticos têm acento privilegiado nesse processo. Por outro lado, há também outras perspectivas, como por exemplo, os Novos Estudos do Letramento $(\mathrm{Nel})$, defendem uma viragem no que tange ao processo de letramento, no sentido de que o letramento não mais deve ter o seu foco exclusivamente na aquisição de habilidades linguísticas, mas sim, considerar também o letramento como uma prática social (FUMO e GIRÃO, 2018).

No presente trabalho, pretendemos evidenciar que a alfabetização é, sim, um processo sistemático e explícito da sua faceta linguística, em que a professora cria situações didáticas para ajudar a criança a compreender o princípio alfabético, a operá-lo e a se apropriar do sistema 
alfabético de escrita e de suas convenções por processos distintos daquele pelo qual ela se apropriou da cadeia sonora da fala. Ou seja, mostrar que a alfabetização é uma prática "que requer que o aluno adquira competências específicas para que possa se apropriar do conteúdo lido de forma a significá-lo e ressignificá-lo no seu dia-a-dia" (RANGEL e MACHADO, 2012, p. 2). No entanto, corroborando a concepção de alfabetização defendida por Magda Soares (2016) como sendo um processo complexo que envolve três facetas distintas e indissociáveis (a linguística, a interativa e a sociocultural), observaremos que algumas questões precisam ser equacionadas quando se trata da infância e da literatura, especialmente no que diz respeito às interações humanas.

Problematizaremos em torno das duas vertentes que, atualmente, vêm ocupando os acentos no debate acerca da alfabetização, com a intenção clara de pautar os encaminhamentos didáticos dos/as professores/as alfabetizadores/as: a construtivista e a fonológica. Quais as contribuições dessas duas perspectivas teóricas para o ensino da leitura e da escrita de textos literários no primeiro ano do ciclo de alfabetização ${ }^{4}$ ? Qual concepção de infância fundamenta as práticas pedagógicas de uma e outra corrente teórica?

A seguir, fundamentadas no pensamento de Todorov (2010) que compreende a função social da arte como aquela que amplia os horizontes de percepção, imaginação e criação tanto da criança quanto da pessoa adulta, buscaremos responder a cada uma dessas problematizações com vistas a contribuir para o debate sobre a intrínseca relação entre alfabetização, literatura e infância.

\section{IMPLICAÇÕES DIDÁTICAS PARA O APRENDIZADO DA LEITURA E DA ESCRITA DO TEXTO LITERÁRIO}

Se o todo é complexo e multifacetado, se cada faceta é de específica, cada uma só pode ser investigada isoladamente. No entanto, quando o fenômeno passa a ser objeto não de pesquisa, mas de aprendizagem e de ensino, é adequado agir como os cegos? Eleger uma ou outra função, uma ou outra faceta? Ou é preciso reconstruir o todo? (SOARES, 2016, p. 33)

Para a promoção do ensino e da aprendizagem da leitura e da escrita, a professora precisará lançar mão de princípios linguísticos, psicológicos e sociais que, pautados em concepções teóricas acerca da educação, linguagem e infância, são convertidos em procedimentos e estratégias favorecedoras do desenvolvimento pleno das crianças, ajudando-as na superação

\footnotetext{
${ }^{4}$ Consideramos o ciclo de alfabetização como sendo do $1^{\circ}$ ao $3^{\circ}$ ano do ensino fundamental, com crianças entre 6 a 8 anos de idade. Cf. BAZZO, 2015.
} 
das possíveis dificuldades e no enfrentamento dos desafios que interferem nesse processo de internalização da língua escrita.

Em seu livro intitulado "Alfabetização: a questão dos métodos", Magda Soares apresenta uma instigante discussão sobre a necessidade de criar caminhos metodológicos para ir ao encontro da criança e, para tal, entre outras questões, se faz premente "conhecer seu curso, seus meandros, as dificuldades que se interpõem” nesse caminho (2016, p. 352). Por esta razão, ela considera imprudente trilhar um único método, definido a priori por convencionais métodos de alfabetização - ou o seu contrário, abandonar qualquer possibilidade de orientação que ajude a conhecer os caminhos de aprendizagem das crianças, pois, segundo Soares, os "alfabetizadores (as) dependem do conhecimento dos processos cognitivos e linguísticos de desenvolvimento e aprendizagem da língua escrita - para orientar seus próprios passos e os das crianças" (2016, p. 352).

Considerando a importância de conhecer e orientar com segurança o processo de alfabetização, Soares (2016) apresenta uma reflexão em torno de três facetas que o compõem - sociocultural, interativa e linguística, e são inerentes ao processo inicial de aprendizagem da leitura e da escrita. No bojo dessa discussão, a autora tece algumas reflexões à luz de dois paradigmas, o construtivista e o fonológico, afirmando que:

A dimensão do linguístico não é a mesma em todas as facetas, de modo que o adjetivo foi reservado para aquela faceta em que essa dimensão predomina: a dimensão do processo de aprendizagem inicial da língua escrita que se volta para a fixação da fala em representação gráfica, transformando a língua sonora - do falar e do ouvir - em língua visível - do escrever e do ler. Esse processo de representação da cadeia sonora da fala na forma gráfica da escrita constitui uma tecnologia que envolve a aprendizagem do sistema alfabético-ortográfico e das convenções que governam o uso desse sistema. (SOARES, 2016, p. 37-38 - grifos da autora)

A faceta linguística é, portanto, segundo Soares (2016), imprescindível, mas não suficiente, para o processo inicial de aprendizagem da língua escrita, a qual se reserva o nome de alfabetização, isto é, refere-se à aprendizagem do sistema alfabético-ortográfico que conduz à leitura e à produção de palavras escritas. Portanto, seu objeto do conhecimento é essencialmente linguístico, o sistema alfabético-ortográfico de escrita, não sendo suficiente, uma vez que a compreensão e a apropriação dos aspectos da comunicação, incluindo o processo de alfabetização, implica um pareamento entre forma e significado, bem como a consideração das experiências prévias do sujeito alfabetizando. Por não ser a dimensão linguística suficiente, a professora precisa se atentar para as duas facetas complementares: a sociocultural e a interativa. 
Na visão de Soares (2016), a faceta sociocultural se refere aos usos e às funções da língua escrita em diferentes contextos sociais e culturais e em diferentes eventos de letramento, portanto, estão presentes outros elementos não linguísticos, sendo, portanto, seu objeto de conhecimento os usos e as funções da língua escrita. Já a faceta interativa da alfabetização, ainda de acordo com a autora, diz respeito ao uso interativo da língua escrita para a interação, a compreensão e a produção de textos, o que envolve, para além da dimensão linguística, elementos textuais e pragmáticos, não exclusivamente linguísticos. Logo, o objeto de conhecimento dessa faceta é o uso da língua para fins de interação.

Ao concebermos a alfabetização pelo prisma da indissociabilidade e complementariedade entre as dimensões (linguística, sociocultural e interativa) que a constituem, a expectativa é que o trabalho com o texto literário supere as vertentes ingênuas, superficiais e desarticuladas das dimensões éticas, poéticas e estéticas, que transformam a literatura, concebida como arte (BAZZO e CHAGAS, 2014), em instrumentos subordinados aos conhecimentos técnicos dos mecanismos de funcionamento do sistema alfabético-ortográfico da escrita.

Tomando como horizonte epistemológico a concepção de alfabetização ora ressaltada, é possível que o texto literário cumpra o seu papel de ajudar a cada um dos envolvidos a viver melhor e a "responder melhor à sua vocação de ser humano" e possa, por esse motivo, aprender a se distanciar e a se identificar com os valores dos outros, sensibilizando-se, estranhando-se e sendo provocado ou afetado pelo seu destino, suas felicidades e sofrimentos, o que "fazem o mundo real se tornar mais pleno de sentido e mais belo" (TODOROV, 2010, p. 24).

O mais importante, por isso, é que, num ensino focado no aprendizado das primeiras palavras (lidas e escritas), o texto literário contribua para a perfectibilidade do espírito humano e da cultura. A proposta de ensino da leitura e da escrita, que resulta dessa articulação entre literatura e alfabetização, portanto, haverá de promover a apropriação "de uma linguagem artística, em sua beleza, em suas possibilidades de ampliação de horizontes e de percepções diferenciadas de mundo" (PAIVA e MACIEL, 2008, p. 120). Isto significa que, concebido como arte, o texto literário auxiliará as crianças a construírem sentidos e significações vigorosos em torno da realidade e da vida em geral. Por isso, concordando com Soares,

É obrigação da escola dar amplo e irrestrito acesso ao mundo da leitura, e isto inclui a leitura informativa, mas também a leitura literária: a leitura para fins pragmáticos, mas também a leitura de fruição: a leitura que situações da vida real exigem, mas também a leitura que nos permita escapar por alguns momentos da vida real. (SOARES, 2002, p. 6)

Considerando sua dimensão poética e estética, o texto literário favorecerá o exercício de estar 
no mundo e se relacionar com as coisas, os lugares e as pessoas, percebendo os sentimentos, as sensações, as intuições e, por meio de capturas de redes semióticas socializadas, os entendimentos acerca da existência humana. Nesse movimento, portanto, criam-se conceitos, categorias e criam-se conhecimentos, humanizam-se todos.

\title{
ENSINAR E APRENDER A LER TEXTOS LITERÁRIOS: PORQUE ELES NOS AJUDAM A VIVER
}

\begin{abstract}
Hoje me pergunto por que amo a literatura, a resposta que me vem espontaneamente à cabeça é: porque ela me ajuda a viver. Não é mais o caso de pedir a ela, como ocorreria na adolescência, que me preservasse das feridas que eu poderia sofrer nos encontros com pessoas reais; em lugar de excluir as experiências vividas, ela me faz descobrir mundos que se colocam em continuidade com essas experiências e me permite melhor compreendê-las. Não creio ser o único a vê-la assim. Mais densa e mais eloquente que a vida cotidiana, mas não radicalmente diferente, a literatura amplia o nosso universo, incita-nos a imaginar outras maneiras de concebê-lo e organizá-lo. Somos todos feitos do que os outros seres humanos nos dão: primeiro nossos pais, depois aqueles que nos cercam; a literatura abra ao infinito essa possibilidade de interação com os outros e, por isso, nos enriquece profundamente. (TODOROV, 2010, p. 23-24)
\end{abstract}

Todorov (2010) pontua que as palavras poéticas são, afinal, aquelas com vigor que se conformam como expressões e efeitos de sentidos e de existência. Elas são, ao nosso ver, a potência criadora e vital da possibilidade de humanizar os humanos, isto é, torná-los seres que sentem, que se emocionam e, fundamentalmente, que pensam e agem a partir dessa fonte inesgotável de atribuição de sentido.

As palavras são, portanto, as "mensageiras" de necessidades, desejos, interesses e motivações humanas - pulsão de vida e/ou de morte. Com elas, os serem humanos nomeiam o mundo e necessitam compartilhar esse mundo produzido simbolicamente, objetivando-o com os outros. Nesse processo de objetivação, a interação eu-outro traduz e ao mesmo tempo cria um modo de vida social em movimento, o que Bazzo e Chagas (2014) compreenderão que se trata da linguagem manifestada pelo desejo de escuta e acolhida de todos os seres humanos. Para as autoras, a produção da linguagem favorece a comunicação e a interação, que, por haver intencionalidade e finalidade implicadas, promove a superação de mero "estoque" de palavras. Dessa maneira, concebida como uma forma de interação e um espaço de constituição de subjetivações, a linguagem instaura o processo de criação e invenção humana ao mesmo tempo em que inaugura as instâncias de poder pela palavra, pelo verbo que se faz ação.

Pautada em teóricos como Humberto Eco e Antonio Candido, Eliane Debus (2017, p. 38) 
defende a literatura como "patrimônio cultural" e destacamos a sua "força humanizadora". Na sua compreensão, "o texto literário partilha com os leitores, independentemente da idade, valores de natureza social, cultural, histórica e/ou ideológica por ser uma realização da cultura e estar integrado num processo comunicativo" (DEBUS, 2017, p. 38). De certo modo, há um consenso mais ou menos tácito entre a maioria dos professores e professoras da educação básica acerca desse entendimento da literatura (como "patrimônio cultural" e direito à humanização) e da linguagem (como lócus de produção de discursos e constituição de sujeitos).

De acordo com Paiva e Maciel (2008), um dos paradoxos é que, se por um lado, os docentes precisam dar acesso e escolarizar o texto literário, por outro, eles precisam preservar suas especificidades de linguagem artística.

Promover o encontro das crianças com o texto literário, desde o início do processo de alfabetização, constitui, como já foi dito antes, um desafio, tanto para quem propõe como para quem se dispõe à leitura. O professor é, sem dúvida, um sofrido protagonista nesse processo. Que ferramentas utilizar para aproximar s crianças da leitura literária sem tornar a Literatura intangível ou sacralizada, em suma, sem tornar inexorável a tarefa didática? (PAIVA e Maciel, 2008, p. 118)

No nosso entendimento, essa tensão ainda se mantém no espaço escolar, geralmente, por questões metodológicas, sobretudo, porque, os professores ainda continuam a ignorar o trabalho sistemático e intencional de alfabetização mediante o uso efetivo das palavras das crianças produzidas a partir da experiência estética e poética, que foi resultante da interação e mediação de práticas literárias - às vezes, também pelos atravessamentos e instabilidades de concepção acerca da literatura e da formação de leitores de textos literários. Também é prudente recorrermos a uma recomendação de Magda Soares (2011, p. 22), ao abordar sobre a escolarização da literatura infantil e juvenil, para corrigirmos criticamente qualquer posicionamento preconceituoso em relação ao "saber escolar", pois, segundo a autora, não se pode atribuir, em tese, conotação pejorativa à escolarização, porque estaríamos negando a própria escola e incorreríamos no erro de perspectiva: "o que se deve negar não é a escolarização da literatura", mas sua "inadequada, errônea e imprópria escolarização", traduzindo-se em deturpação, falsificação e distorção, "como resultados de uma pedagogização ou uma didatização mal compreendidas".

Quiçá as escolas de educação básica conseguissem criar as condições objetivas necessárias para que os/as estudantes, conforme ressaltou Todorov (2010), entendessem que a literatura os "ajuda a viver melhor" e, porque amplia o universo e provoca a imaginação, abrange as experiências vividas, possibilitando que eles descubram percepções de mundo, de sujeitos e de sociedade que se intercruzam com essas experiências e favoreçam uma melhor compreensão sobre si mesmos, sobre os outros e os demais aspectos que compõem uma vida em sociedade. Para além de ajudar no processo de apropriação do sistema de escrita alfabético-ortográfico, 
porque ativa o imaginário e o simbólico por meio de uma prática mediada e dialógica, a literatura contribuirá sobremaneira para a formação do hábito da leitura como uma necessidade de existir com sentido, o que favorecerá a formação de uma postura crítica e, por isso, de uma indiscutível capacidade de problematização, argumentação e criatividade.

A presença do texto literário no processo de alfabetização exigirá que os professores pensem desenhos curriculares, didático-pedagógicos, diversificados, especialmente relativo à prática de mediação de leitura: ler para conversar em roda, ler para pensar sobre uma questão, ler para encontrar informações, ler para rir, ler para brincar, ler para contemplar, ler para se emocionar, ler para imaginar, ler para criar, ler para ler simplesmente. E estes aspectos são de fundamentais para o desenvolvimento cognitivo e sóciocultural na vida do/a estudante como ser intelectual e social.

Numa sala de crianças entre 6 e 7 anos de idade, a professora, no início, no meio ou depois do intervalo ou, até mesmo, no final da aula, leu para e com as crianças a fábula intitulada "Conversas sobre estrelas", de Shahrukh Husain e Micha Archer (2017), traduzida por Monica Stahel:

Numa noite de verão, sob um ar perfumado e estrelas brilhando no céu, os homens de Akshehir estavam sentados ao ar livre, sorvendo um delicioso café em xícaras de vidro. Descansavam após o dia de trabalho duro, falando disso e daquilo, até que a conversa foi parar nas estrelas. Alguns acreditavam que as estrelas podiam dizer que tipo de pessoa era cada um, ou o que aguardava a humanidade.

"Então, Khoja”, perguntou Yunus, "sob qual estrela você nasceu?”

Mulá Nasrudin tomou outro gole de café, desfrutando do aroma das sementes de cardamomo moídas. "Foi há muito tempo", ele respondeu, "mas tenho certeza de que foi sob Cordeiro. Sim, isso mesmo. Lembro-me claramente de minha mãe dizer que nasci sob o signo do Cordeiro."

Os homens começaram a rir.

"Esse signo não existe", disse Yunus. "Você não quis dizer Carneiro?"

Nasrudin pousou a xícara e fitou o céu estrelado. "Faz quarenta anos que meu horóscopo se fixou", ele respondeu. "Aquele cordeiro certamente já cresceu e se tornou carneiro.” (HUSAIN, 2017, p. 13)

Imediatamente após a leitura, a professora distribuiu algumas folhas de papel, lápis de cor e solicitou que as crianças desenhassem estrelas, carneiro e cordeiro. Posteriormente, ela trabalhou com as letras "S" e "C" e explicou para as crianças os sons de cada uma delas na posição inicial, final e antes de vogais e consoantes. 
Ao considerarmos as implicações da literatura para a alfabetização, essa proposta didática está coerente com a concepção ora apresentada - literatura: obra de arte e direito à humanização? $\mathrm{E}$, se pensarmos especificamente, nas facetas (interativa, linguística e sociocultural) que compõem a alfabetização, ela é coerente?

Essas perguntas, em si, já trazem a sua negativa. Verdadeiramente, ao ignorar o processo de interlocução, diálogo e mediação semiótica, a professora inviabiliza a ambas as perspectivas adotadas para o aprendizado da leitura e da escrita, o que compromete o aprendizado, a socialização e o desenvolvimento integral das crianças. O texto literário exige outra qualidade de trabalho, exige entrega e disposição, em especial e inicialmente da professora. Pois, "a fruição da obra literária, assim, reclamará de seu leitor uma disponibilidade singular para o engenho de hipóteses, convocando uma razão lúdica e criativa (CUNHA, 2017, p. 196).

Outra professora, diferentemente da anterior, convidou as crianças a um diálogo sobre a obra lida. Entre outras questões, ela perguntou: "João, o que significa conversas sobre estrelas"? "Maria, você já conversou com amigos ou familiares sobre estrelas?" Após ouvir as crianças, ela as relembrou que os homens estavam reunidos, depois de um dia duro de trabalho, sentados ao ar livre e tomavam uma xícara de café. Olhando nos olhos de Pedro, ela indagou: "Oh, Pedro, quando ouviu essa história, o que você imaginou? O que sentiu?". E continuou a problematização em torno da obra, instigando as crianças a conversarem sobre as sementes de cardamomo moídas, sua origem e suas propriedades nutritivas; sobre o Mulá Nasrudim, sua origem e a história dos povos islâmicos; sobre os signos do islamismo e o profeta Maomé; sobre as diferenças crenças religiosas e a beleza da diversidade humana diante dos desafios e das possibilidades de bem-viver em sociedade.

Enfim, essas conversas sobre estrelas geraram outras e muitas possibilidades de interação, estudos e aprofundamentos de conhecimentos sobre as relações multiétnicas e a necessidade de uma convivência harmoniosa entre povos de culturas diferentes e a importância das representações simbólicas para o aprimoramento das nossas compreensões sobre tudo o que há sob o céu e a terra, o universo e o infinito. Na continuidade do trabalho, a professora pediu para as crianças como atividade complementar que refletissem com seus familiares ${ }^{5}$ sobre as estrelas; à noite, buscassem contemplá-las e, de alguma forma, fizessem um registro do momento. A professora ainda compartilhou com as crianças imagens de estrelas, continuando o diálogo sobre o universo e mais alguns astros que o constitui.

\footnotetext{
${ }^{5}$ Prudente que as famílias sejam coadjuvantes nesse processo. Para tanto, importante noticiá-las e integrá-las aos projetos e atividades cotidianas do processo formativo das crianças com antecedência.
} 
Após essas conversas e atividades mobilizadas em razão da leitura, é provável que a literatura já tenha cumprido a sua função social. A partir desse trabalho interpretativo- compreensivo, as crianças se tornaram curiosas para ler e escrever sobre seus signos e a criá-los a partir da ativação do imaginário e do desejo de saber, de conhecer e compartilhar seus aprendizados. Até aqui, tudo indicou que o foco foram as estrelas. E o cordeiro e o carneiro? Eis mais uma possibilidade de atalho para continuar a conversa e os aprofundamentos dos estudos acerca da sabedoria milenar do mundo islâmico: a astrologia e seus efeitos sobre a vida das pessoas aqui no Brasil.

Leitura em jornais e revistas sobre os signos, discussão sobre a crença de uns e a descrença de outros seres humanos em torno da temática, bem como observação, desenho, pintura, cerâmica, gravura, colagem, fotografia, escultura e outros exercícios de criação e contemplação cujo motivo seja cada um dos signos podem potencializar ainda mais esse processo. Se por um lado as especulações em torno das possibilidades didático-pedagógicas para a promoção do aprendizado da leitura do texto literário ficaram evidenciadas, por outro, falta elucidar como a professora poderá criar as condições efetivas para a apropriação do sistema de escrita alfabético-ortográfico pelas crianças, ou seja, para a promoção do aprendizado da escrita do texto literário.

\title{
ENSINAR E APRENDER A ESCREVER TEXTOS LITERÁRIOS: OU PARA DAR NOMES AOS CORDEIROS E CARNEIROS E MATERIALIZAR AS ESTRELAS
}

\begin{abstract}
A língua não é uma entidade abstrata, exterior aos que a usam; é uma atividade social e, como tal, traz a marca dos que a usam. Por exemplo, a marca de idade que têm - o modo de falar de adolescentes é diferente do mundo de falar de seus pais; a marca do sexo a que pertencem - estudos sociolinguísticos apontam que homens e mulheres usam de modo diferente os recursos que a língua oferece; a marca da profissão que exercem - comunidades profissionais têm modos de falar específicos de sua profissão; a classe social a que pertencem - pessoas de classes privilegiadas usam modos de falar diferentes dos modos de falar de pessoas de classes desfavorecidas. (SOARES, 2017, p. 140 - grifos da autora)
\end{abstract}

Se "a língua não é uma entidade abstrata e exterior aos que a usam”, conforme defende Soares (2017, p. 140), posição semelhante a de Severo (2014), ao atestar que línguas não devem ser encarradas como objetos a serem impostos aos falantes, mas sim como produtos de práticas sociais e dialógicas desses falantes, então, a questão será: qual será a língua escrita e falada reconhecidamente das crianças no processo inicial de aprendizado da escrita? Sobre o que as crianças desejam escrever? Quais são suas motivações para o aprendizado do texto escrito? Elas se interessam pela escrita? Como saber? É preciso conversar sobre essas e outras questões 
que tangenciam esse assunto com as crianças?

Será que as crianças têm disposição para escrever um livro sobre as estrelas e/ou sobre os carneiros? Para que escreveriam um livro? Por que o escreveriam? Para quem elas o escreveriam? Como seria esse livro? Um livro de fábula? De poemas? Quais textos? Como escrever quando ainda não se sabe? Será no processo do fazer que se aprenderá. Portanto, é preciso começar o projeto de escritura, nomeando as coisas. É preciso dar nome "aos cordeiros e aos carneiros" e materializar as estrelas.

Ademais, considerando que as tecnologias digitais da informação e da comunicação já estão assimiladas e incorporadas no cotidiano escolar, tanto a produção do livro quanto a sua difusão serão efetivadas e atualizadas por meio dos artefatos tecnológicos do nosso tempo presente e das redes virtuais.

Lembramos que se trata de um livro escrito em língua portuguesa para crianças entre 6 e 7 anos de idade. O que tem em um livro escrito por crianças? Tema? Título? Ilustração? Autoria? Eis uma possibilidade de começo, tendo em vista que "compete ao homem, 'ser linguístico', nomear as coisas. Este ato não é arbitrário, porque, ao fazê-lo, ele identifica o sentido de cada coisa, presente na entidade mental' que se expressa” (ZILBERMAN, 2008, p. 169).

Corroborando a vertente dialógica e simbólica da linguagem, a pesquisadora Ludmila Thomé de Andrade (2017, p. 530) ressalta que na perspectiva discursiva para o aprendizado da língua escrita o plural é singular, enfatizando algumas ondas na história da alfabetização: o Construtivismo, que se estabeleceu como uma das abordagens com maior destaque, mas sem efeito efetivo para o aprendizado da língua escrita; o Letramento, que também logrou um "estatuto de inovação para se pensar a didática da língua escrita" no fim dos anos 1990, porém se vinculou fortemente a questões voltadas às práticas sociais e não elaborou "as consequências pedagógicas de alguns de seus preceitos teóricos"; o Método Fônico ${ }^{6}$, que embora se apresente como "uma inovação no cenário brasileiro da alfabetização" significa um retrocesso histórico, sobretudo porque retoma "o tempo da querela dos métodos" tradicionais e que já havia sido superado pelo boom do construtivismo (ANDRADE, 2017, p. 531).

De igual modo, Bazzo (2015) destaca o poder das interlocuções e do trabalho dialógico para a

\footnotetext{
${ }^{6}$ Segundo Andrade, esse método "foi impulsionado mais recentemente, através de diversas iniciativas privadas e, inusitada e surpreendentemente, vem ganhando terreno e chega a criar bolsões de influência não só no ensino privado, mas também no público, através da venda de materiais por fundações e instituições que se arvoram como de pesquisa, alegando um conhecimento 'científico', mas isentando-se de debater com os demais" (ANDRADE, 2017, p. 531). Ademais, registra-se que o atual governo brasileiro instituiu a Política Nacional de Alfabetização, através de Decreto $n^{\circ} 9.765$, de 11 de abril 2019, adotando o método fônico como única estratégia para o ensino e o aprendizado inicial da leitura e da escrita.
} 
promoção da aprendizagem da língua escrita. Com base na perspectiva teórica de Magda Soares (2016), a autora discorre sobre a alfabetização no sentido lato e no sentido restrito, isto é, embora sejam indissociáveis e interdependentes, em sentido amplo, a alfabetização apresenta a sua faceta sociocultural e interativa, especialmente no tocante ao uso social que se faz da leitura e da escrita; e, no sentido restrito, significa o aprendizado do sistema de escrita alfabético-ortográfico de forma sistemática e consciente, ou seja, transferência da cadeia sonora da fala para a forma gráfica da escrita, isto é, sua dimensão linguística propriamente dita. Esse estudo sistemático, direto e explícito, segundo a autora, envolve o estudo da relação entre fonema-grafema para a leitura e grafema-fonema para a escrita.

E como se concretiza tal concepção de ensino e aprendizagem da língua escrita na sua faceta linguística? Há alguns caminhos. Um deles é, acolhendo a palavra das crianças e só com palavras encharcadas de sentido, ensinar para elas a função primordial da palavra nas suas dimensões oral e escrita. Ensiná-las a olhar o mundo grafocêtrico e suas complexidades, traduzi-los e grafá-los novamente em um trabalho ininterrupto de criação, invenção e paixão pelo verbo, pela substância e suas correlações. Para tal, é necessário que os intervenientes em processo de alfabetização tomem uma atitude de intervenção, conjugando as três facetas, linguística, social e interativa, refletindo, constantemente, como atesta Duarte (2018).

Para finalizar, sublinha-se que a escola, a sala de aulas e outros espaços de aprendizagem precisam ser espaços que estimulem o/a estudante a se construir em termos de leitura e escrita recorrendo-se a múltiplos meios, incluindo os textos literários; é preciso transformar a sala de aula em um lugar de desmontagem e montagem dessas palavras, observando-a minunciosamente, ressaltando as suas diferenças e similitudes: cor/d/eiro; car/n/eiro; cor/d/eiro; car/n/eiro; cor/d/eiro; car/n/eiro. Nessa artesania, as crianças vão aprendendo que se escreve com letras, mas que há também outros signos não linguísticos que representam e produzem realidades e significações; que há na nossa cultura um modo de escrever, da direita para a esquerda, de cima para baixo; que podemos representar a língua falada em escrita e viceversa; que podemos, enfim, construir conversas sobre estrelas, perceber que o tempo passa, o mapa se fixou e aquele cordeiro certamente já cresceu e se tornou carneiro.

\section{REFERÊNCIAS}

ANDRADE, Ludmila Thomé de. Alfabetizações numa perspectiva discursiva: só o plural pode ser singular. Revista Contemporânea de Educação, vol. 12, n. 25, p. 521-537, set./dez. 2017.

BAZZO, Jilvania Lima dos Santos. A oralidade na formação linguística do professor alfabetizador. Revista Perspectiva, v. 33, n. 1, p. 55-75, jan./abr. 2015. 
BAZZO, Jilvania Lima dos Santos; CHAGAS, Lilane Maria Moura. Leitura de fruição no programa nacional de alfabetização na idade certa no Estado de Santa Catarina. Revista Linha Mestra, Campinas, SP, ano 8, n. 24, p. 144-162, jan./jul. 2014.

CUNHA, Maria Zilda da. Signos e suportes contemporâneos: notas sobre a literatura infantil e juvenil. In: DEBUS, Eliane; BAZZO, Jilvania Lima dos Santos; BORTOLOTTO, Nelita. Literatura infantil e juvenil: pelas frestas do contemporâneo. Copiart/SC: Unisul, 2017, p. 187-207.

DEBUS, Eliane. A temática da cultura africana e afro-brasileira na literatura para crianças e jovens. Florianópolis, Santa Catarina: NUP/CED/UFSC, 2017.

DUARTE, Kátia Macêdo. O papel do professor na leitura e na escrita nos anos iniciais: um estudo de caso com professores do $3^{\circ} ; 4^{\circ}$ e $5^{\circ}$ anos iniciais do ensino fundamental. Anais $\mathbf{V}$ CONEDU - Congresso Nacional de Educação, V. 1, João Pessoa, Paraíba: Editora Realize, 2018. [ISSN: 2358 8829].

FUMO, Óscar; GIRÃO, Stéphnie Soares. Práticas de letramento acadêmico em Moçambique: análise de um trabalho de escrita de gêneros. Revista do Programa de Pós-graduação em Estudos de Linguagens - UFMS, MS, Campo Grande, Vol. 22, n. 43, p. 91-108. 2018.

HUSAIN, Shahrukh. Fábulas do mundo islâmico. Ilustração de Micha Archer. Tradução de Monica Stahel. São Paulo: Martins Fontes, 2017.

PAIVA, Aparecida; MACIEL, Francisca. Discursos da paixão: a leitura literária no processo de formação de professor das séries iniciais. In: PAIVA, Aparecida; MARTINS, Aracy; PAULINO, Graça; VERSIANI, Zélia. Leituras literárias: discursos transitivos. Belo Horizonte: Ceale; Autêntica, 2008, p. 111-126. (Coleção Literatura e Educação).

RANGEL, Mary; MACHADO, Jane do Carmo. O papel da leitura e da escrita na sala de aula: estratégias de ensino para dinamização dos processos de leitura e escrita. Anais do SIELP, vol. 2, n. 1. Uberlândia: EDUFU, 2012.

SEVERO, Cristine Gorski. Línguas e Estados nacionais: problematizações históricas e implicações. In: SEVERO, Cristine; SITOE, Bento; PEDRO, José. Estão as línguas nacionais em perigo? Maputo: Escolar Editora, 2014. (Coleção Cadernos de Ciências Sociais).

SOARES, Magda. Alfabetização e Letramento. São Paulo: Contexto, 2002.

SOARES, Magda. Alfabetização: a questão dos métodos. São Paulo: Contexto, 2016.

SOARES, Magda. Linguagem e escola: uma perspectiva social. São Paulo: Contexto, 2017. 
SOARES, Magda. A escolarização da literatura infantil e juvenil. In: EVENGELISTA, Aracy Alves Martins; BRANDÃO, Heliana Maria Brina; MACHADO, Maria Zélia Versiani. (Orgs.) A escolarização da leitura literária: o jogo do livro infantil. Belo Horizonte: Autêntica, 2011. (Coleção Linguagem e Educação).

TODOROV, Tzvetan. A literatura em perigo. Rio de Janeiro: Difel, 2010.

ZILBERMAN, Regina. Memória entre oralidade e escrita. In: PAIVA, Aparecida; MARTINS, Aracy; PAULINO, Graça; VERSIANI, Zélia. Leituras literárias: discursos transitivos. Belo Horizonte: Ceale; Autêntica, 2008, p. 165-184. (Coleção Literatura e Educação). 